\title{
Sol de sílica como agente ligante em suspensões cerâmicas
}

\author{
(Silica sol as a binder for ceramic suspensions)
}

\author{
R. D. dos Anjos, R. Salomão, V. C. Pandolfelli \\ Departamento de Engenharia de Materiais - DEMa \\ Universidade Federal de S. Carlos - UFSCar \\ Rod. Washington Luiz, km 235, C.P. 676, S. Carlos, SP 13565-905 \\ renataanjos@polvo.ufscar.br,vicpando@power.ufscar.br
}

\begin{abstract}
Resumo
Recentemente, tem-se dado grande enfoque ao estudo de novos agentes ligantes isentos de cálcio e seu emprego em cerâmicas refratárias. Uma das alternativas sugeridas na literatura é o sol de sílica, capaz de se consolidar por meio da formação de uma rede tridimensional de partículas, garantindo a conformação do corpo cerâmico. No entanto, devido à pouca informação sobre o assunto na área de refratários, faz-se necessário um estudo mais detalhado das interações entre as partículas do sol de sílica com as dos diferentes sistemas cerâmicos em que pode ser adicionada. Tal estudo possibilitaria determinar seu potencial como agente ligante e a otimização do processamento e propriedades dos produtos refratários obtidos. Esse trabalho teve como objetivo investigar o impacto de variáveis como temperatura, dispersante e concentração de agentes de gelificação no comportamento de suspensões de alumina e sol de sílica através de técnicas de reometria. Verificou-se que o sol de sílica pode apresentar bom desempenho como agente ligante para suspensões cerâmicas desde que utilizada a aditivação adequada.
\end{abstract}

Palavras-chave: suspensão cerâmica, sol de sílica, agente ligante, gelificação.

\begin{abstract}
Recently, great efforts have been made on studying calcium-free binder agents and their use in refractory ceramics. The publications suggest silica sol as an alternative binder, which can be gelled through the formation of a three-dimensional network of particles. Therefore, further understanding regarding the interaction between silica sol's and other systems'particles is required. Researches in this area would enable the determination of silica sol's potential as a binder agent and the optimization of the products'process and properties. The objective of this work was to investigate the influence of temperature, dispersant and gelling agents content on alumina suspensions using rheometric techniques. Silica sol presented a good performance as a binder agent for ceramic suspensions when applied with optimized aditivation.
\end{abstract}

Keywords: ceramic suspension, silica sol, gelling agent, gelling.

\section{INTRODUÇÃO}

Agentes ligantes isentos de cálcio têm despertado um grande interesse na área de cerâmicas refratárias. A redução de refratariedade gerada na presença de sílica, aliada à necessidade de cura em condições específicas (ambiente saturado de vapor de água e o tempo mínimo empregado para esta etapa do processamento) têm sido um dos principais problemas dos concretos refratários ligados com cimento à base de aluminato de cálcio. O sol de sílica apresenta-se como uma alternativa interessante para tais aplicações [1]. Trata-se de uma dispersão estável de partículas discretas de sílica amorfa, com diâmetros que podem variar entre 4 e $100 \mathrm{~nm}$. É geralmente produzido a partir de soluções de silicato de sódio, por meio de diferentes métodos que levam a produtos com diferentes concentrações, tamanhos, formas de partícula e faixas de $\mathrm{pH}$ [2].

O sol de sílica é capaz de se consolidar por meio da união de suas partículas e formação de uma rede tridimensional.
Dois mecanismos podem promover essa consolidação: gelificação ou coagulação. $\mathrm{O}$ primeiro envolve a colisão de duas partículas e a formação de ligações siloxano ( $\mathrm{Si}$ $\mathrm{O}-\mathrm{Si}$ ); no segundo, um agente coagulante, geralmente um eletrólito, atua como uma "ponte" entre duas partículas de sílica, unindo-as. A consolidação do sol, seja por gelificação ou coagulação, pode ser influenciada por fatores como $\mathrm{pH}$, tamanho e concentração de partículas, presença de eletrólitos e líquidos orgânicos, além da temperatura [2].

Em uma suspensão cerâmica, a formação dessa rede tridimensional de sílica permite sua conformação. Essa propriedade do sol de sílica pode ser explorada para sua utilização como agente ligante em concretos ou em cerâmicas técnicas, sem o uso de outros ligantes hidráulicos. A resistência mecânica a verde seria obtida pela formação da rede de partículas e não por meio da hidratação do ligante. No caso de concretos refratários, isso aumentaria o seu tempo de estocagem antes da aplicação [1], uma vez que o cimento aluminoso apresenta um prazo máximo de validade, 
mesmo acondicionado em ambiente adequado.

No entanto, como são encontradas poucas publicações a esse respeito, é necessário um estudo mais detalhado das interações entre as partículas do sol de sílica com as dos diferentes sistemas cerâmicos em que ele pode ser adicionado; determinando seu potencial como agente ligante e a otimização do processamento e propriedades dos produtos. Neste trabalho, foram abordados os efeitos da variação de dispersantes, de aditivos que influenciam os mecanismos de consolidação do sol de sílica (denominados agentes gelificantes) e da temperatura nas interações do sol de sílica em um sistema de alumina/sol. Foram utilizadas técnicas de reometria, que permitiram a determinação da viscosidade e dos módulos de armazenamento G’ e de perda G” dos materiais. Esses parâmetros foram utilizados para avaliar a cinética de gelificação das suspensões de alumina com sol de sílica, uma vez que essa reação é acompanhada de aumento na viscosidade durante a transição do material de um estado de fluido viscoso para um de sólido elástico [3].

\section{MATERIAIS E MÉTODOS}

\section{Matérias-primas}

Todos os ensaios foram realizados em suspensões base de alumina e sol de sílica, 56,57\%v de sólidos, homogeneizadas em um misturador de bancada (Ética Equipamentos Científicos S.A.) e avaliadas em um reômetro rotativo RS300 (Thermo Haake, Alemanha). As principais matérias-primas usadas foram sol de sílica Bindzil (Nalco) e alumina A17NE (Alcoa, EUA). Como dispersantes foram utilizados ácido cítrico anidro PA (Synth, Brasil), polietilenoglicol FS10 (SKW Polymers, Alemanha), policarboxilato FS20 (SKW Polymers, Alemanha) e polimetacrilato de sódio Darvan 7S (R. T. Vanderbilt Company, Inc., EUA). Foram testados como agentes gelificantes óxido de magnésio, cloreto de magnésio, sulfato de magnésio, hidróxido de cálcio e sulfato de cálcio, todos grau PA (Synth, Brasil). Esses agentes foram escolhidos por apresentarem uma ampla faixa de valores de solubilidade no $\mathrm{pH}$ da suspensão, basicidade e mobilidade do eletrólito.

\section{Ensaios de dispersão}

Os ensaios de dispersão da suspensão foram realizados com uma ferramenta cilindro coaxial, sob taxa de cisalhamento constante de $50 \mathrm{~s}^{-1}$ durante $30 \mathrm{~s}$, em temperatura constante a $25^{\circ} \mathrm{C}$ [4].

\section{Ensaios de gelificação}

A gelificação foi avaliada em ensaios oscilatórios efetuados no modo de operação controle de tensão. Os testes foram realizados em freqüência e tensão constantes de 1 $\mathrm{Hz}$ e $1 \mathrm{~Pa}$, respectivamente, com a ferramenta vane. Esses parâmetros foram determinados em testes preliminares e utilizados para garantir que a análise fosse feita no regime viscoelástico linear. $\mathrm{O}$ ensaio visa medir os módulos de armazenamento G' e perda G” em função do tempo. A ocorrência da reação de gelificação foi detectada pelo aumento do valor desses módulos. Durante os experimentos, a superfície da suspensão foi recoberta com uma camada de óleo para evitar secagem [4].

\section{Ensaios de resistência mecânica}

Os ensaios de resistência mecânica (compressão diametral - Norma ASTM C 496-90) foram realizados em amostras cilíndricas $(\mathrm{h}=\mathrm{d}=20 \mathrm{~mm})$ submetidas à temperatura de $25^{\circ} \mathrm{C}$ por $48 \mathrm{~h}$ e, a seguir, à temperatura de $50^{\circ} \mathrm{C}$ por $24 \mathrm{~h}$ em ambiente sem vapor de água para gelificação/coagulação e secagem dos corpos. Utilizou-se um equipamento de ensaios universal (MTS 810, EUA) e uma câmara climática (Vötsch modelo 20-20, Alemanha) para os ensaios mecânicos.

\section{RESULTADOS E DISCUSSÃO}

Em uma primeira etapa foram realizados os ensaios de dispersão para se determinar potenciais candidatos para dispersão do sistema alumina/sol de sílica. Esses resultados são ilustrados na Fig. 1, e na Tabela I são apresentados os teores ótimos determinados para os vários dispersantes testados.

Tabela I - Teor otimizado de dispersante para suspensões de alumina e sol de sílica.

[Table I - Optimized dispersant content for alumina and silica sol suspensions.]

\begin{tabular}{ccc}
\hline Dispersante & Teor $\left(\mathrm{mg} / \mathrm{m}^{2}\right)$ & Viscosidade (mPas) \\
\hline Ácido cítrico & 1,18 & 460 \\
FS20 & 1,67 & 303 \\
FS10 & 1,92 & 503 \\
Darvan 7S & 0,56 & 616 \\
\hline
\end{tabular}

Observou-se que a viscosidade de suspensões de alumina e sol de sílica pode ser reduzida, embora não muito, com a adição de agentes dispersantes. Esse fato indica que, no sistema estudado, a utilização de um dispersante pode auxiliar o processamento, embora a literatura descreva casos em que essa função seja desempenhada pelo próprio sol de sílica [1].

Para verificar o impacto da presença dos dispersantes na consolidação do sol de sílica foram realizados ensaios de gelificação em suspensões de alumina e sol de sílica com adição dos dispersantes testados segundo os teores ótimos determinados e de $0,3 \%$ p (função do peso do sol de sílica) de $\mathrm{MgO}$. A Fig. 2 apresenta os resultados obtidos.

Para o sistema alumina-sol de sílica, verificou-se que a 


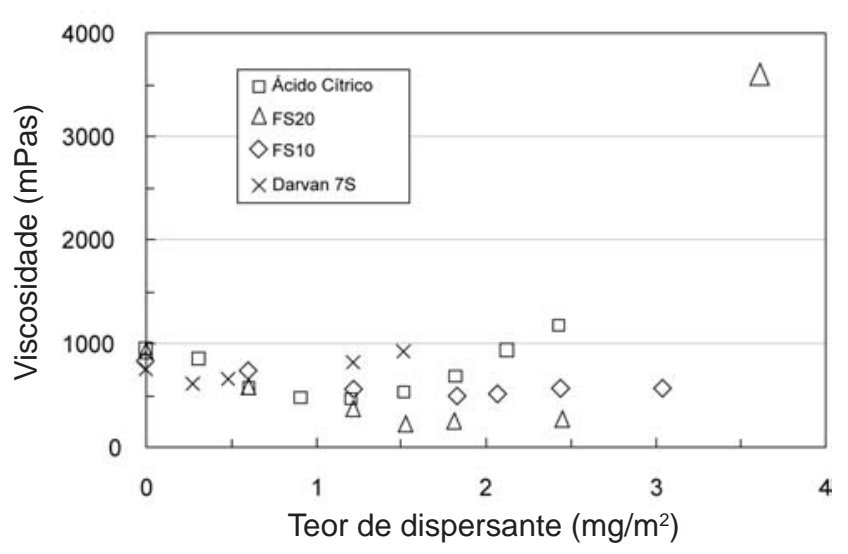

Figura 1: Viscosidade em função do teor de dispersante para suspensões de alumina e sol de sílica.

[Figure 1: Viscosity as a function of dispersant content for alumina and silica sol suspensions.]

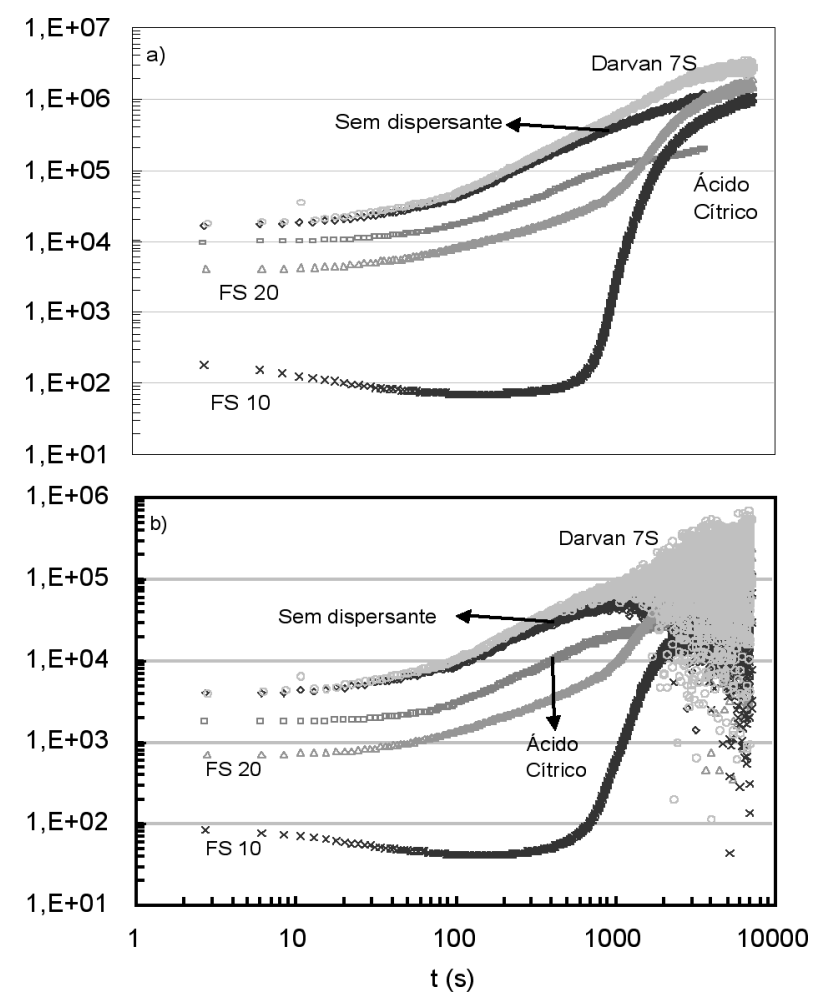

Figura 2: Suspensão de alumina e sol de sílica com 0,3\%p de $\mathrm{MgO}$ e adição de diferentes dispersantes a $25^{\circ} \mathrm{C}$; a) G' e b) G” em função do tempo.

[Figure 2: Alumina and silica sol suspension with 0,3\%wt of $\mathrm{MgO}$ and addition of different dispersants at $25^{\circ} \mathrm{C}$; a) G' and b) G” as a function of time. ]

consolidação ocorre quando o módulo de armazenamento G’ atinge o valor de $10^{6} \mathrm{~Pa}$ e se estabiliza nesse patamar, ao mesmo tempo em que os valores do módulo de perda G” começam a apresentar grande dispersão. A amostra dispersa com FS10 apresentou um comportamento bastante favorável ao processamento. Embora não promova a menor viscosidade (Fig. 1), os módulos G' e G" inicialmente possuem valores bem menores que os das outras suspensões e se elevam em maiores taxas, alcançando os mesmos valores finais em um intervalo de tempo semelhante. Isso implica em uma melhor trabalhabilidade da suspensão durante o processo de conformação, uma vez que o comportamento é marcado por duas fases distintas: início e aceleração da reação de consolidação. Devido a esse comportamento, o FS10 foi escolhido como o aditivo mais indicado para esse sistema.

A influência dos agentes dispersantes na consolidação das suspensões foi avaliada também por medidas de $\mathrm{pH}$ após sua adição. Os valores se encontram na Tabela II.

Tabela II - Valores de pH para suspensões de alumina e sol de sílica com adição de diferentes dispersantes (teor otimizado Tabela I).

[Table II - pH values for alumina and silica sol suspensions with addition of different dispersants (Table 1 optimized content).]

\begin{tabular}{cc}
\hline Tipo de Dispersante & $\mathrm{pH}\left(25^{\circ} \mathrm{C}\right)$ \\
\hline Sem dispersante & 10,3 \\
Ácido cítrico & 7,3 \\
FS20 & 9,4 \\
FS10 & 9,8 \\
Darvan 7S & 10,3 \\
\hline
\end{tabular}

Os resultados da Fig. 2 e os da Tabela II podem ser relacionados. A velocidade da reação de consolidação do sol de sílica pode ser controlada pela variação do $\mathrm{pH}$ (a taxa máxima é atingida em pH 5), ou pela adição de eletrólitos [2]. A adição de Darvan $7 \mathrm{~S}$ não provocou mudança no $\mathrm{pH}$, mas provavelmente liberou íons $\mathrm{Na}^{+}$na suspensão, resultando nos maiores valores de módulos obtidos. O ácido cítrico abaixou consideravelmente o pH, o que, a princípio, também favorece a consolidação. No entanto, a Fig. 2 mostra que a suspensão com ácido cítrico não apresentou valores superiores de G' e G” quando comparadas com a suspensão sem aditivo. Esse fato pode estar associado à reação de complexação entre o ácido cítrico e o $\mathrm{MgO}$, gerando citrato de magnésio, que é insolúvel nessa faixa de $\mathrm{pH}$. Os dispersantes FS10 e FS20 provavelmente não atuaram segundo esses mecanismos, pois não são iônicos. Sua atuação pode estar associada à presença de moléculas de elevado peso molecular, que promovem a floculação, atuando como pontes para união das partículas [2].

A consolidação do sol de sílica pela adição de eletrólitos pode ser realizada pela adição, em geral, de sais inorgânicos, apesar de também poderem ser usados óxidos ou hidróxidos e líquidos orgânicos [2]. Sendo assim, foram realizados ensaios de gelificação em suspensões de alumina e sol de sílica com adição dos seguintes compostos inorgânicos: $\mathrm{MgO}, \mathrm{Mg}(\mathrm{OH})_{2}, \mathrm{MgCl}_{2}, \mathrm{MgSO}_{4}, \mathrm{CaO}, \mathrm{Ca}(\mathrm{OH})_{2}, \mathrm{CaCl}_{2}$ e 


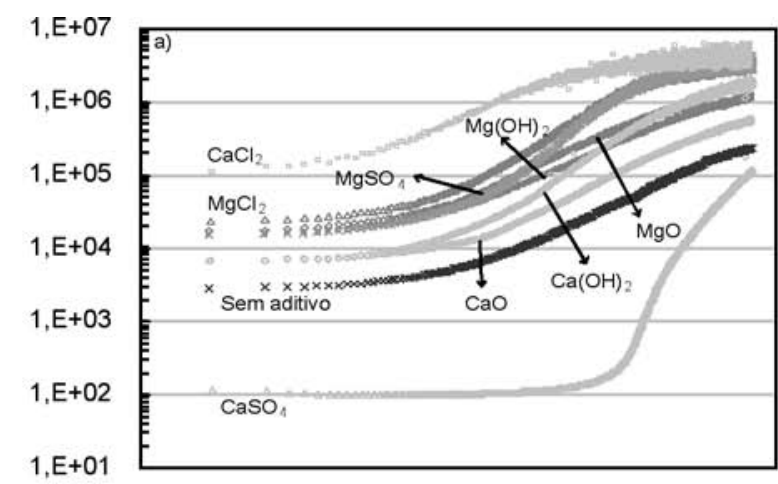

$t(s)$

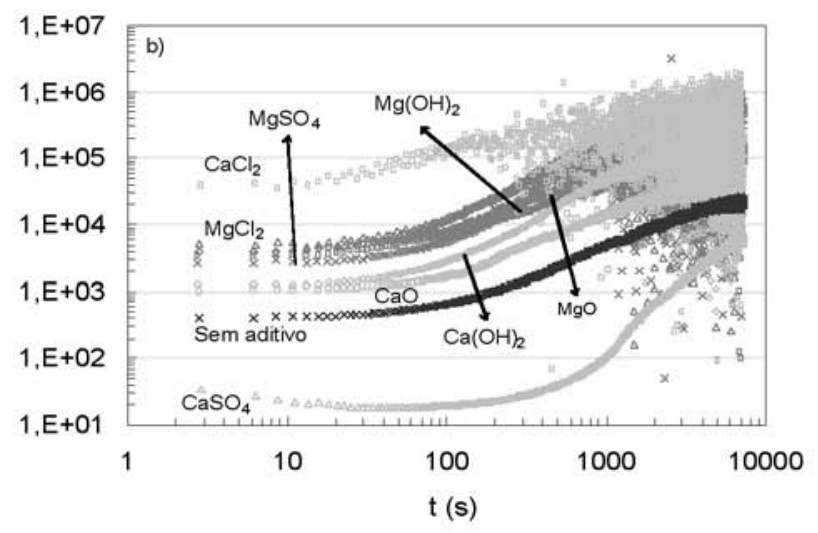

Figura 3: Suspensão de alumina e sol de sílica com adição de diferentes compostos inorgânicos a $25^{\circ} \mathrm{C}$; a) G' e b) G” em função do tempo. [Figure 3: Alumina and silica sol suspension with addition of different inorganic compounds at $25^{\circ} C$; a) $G$ ' and b) $G$ ” as a function of time.]

$\mathrm{CaSO}_{4}$. Inicialmente, foram realizados ensaios com $\mathrm{MgO}$, no teor de $0,3 \%$ p em função do peso da suspensão de sol de sílica. Os outros compostos foram adicionados em quantidades equivalentes ao mesmo teor em mol dos cátions de $\mathrm{MgO}$ adicionados, a fim de se ter uma base comparativa $\left(7 \times 10^{-5} \mathrm{~mol}_{\text {cátion }} / \mathrm{g}_{\text {sol de silica }}\right)$. Aditivos dispersantes não foram adicionados visando isolar a influência desses compostos sobre o comportamento dos módulos de armazenamento e de perda. A Fig. 3 apresenta os resultados juntamente com o de uma curva referência obtido para uma suspensão sem aditivo gelificante.

Sem a adição de um agente gelificante, o sol de sílica apresentou aumento dos módulos de armazenamento e perda, mas em velocidades menores que as observadas nas suspensões com esses aditivos. É razoável supor que a suspensão de referência se consolidará, atingindo valores similares aos módulos G’ e G” das suspensões com aditivo, porém em um intervalo de tempo muito maior. No entanto, para aplicações tecnológicas, esse período é muito longo, podendo-se afirmar que na prática não houve consolidação e que um agente gelificante deveria ser preferencialmente adicionado.

Todos os aditivos, com exceção do $\mathrm{CaSO}_{4}$, aceleraram a reação de consolidação do sol de sílica, o que se observa pelo aumento dos módulos G’e G’. Fisicamente, a suspensão se tornou mais elástica ao mesmo tempo que aumentou sua capacidade de dissipar energia quando deformada no limite viscoelástico linear. A rapidez com que a suspensão foi consolidada, considerando-se do agente mais rápido para o mais lento, foi assim definida: $\mathrm{CaCl}_{2}, \mathrm{MgCl}_{2}, \mathrm{MgSO}_{4}$, $\mathrm{Ca}(\mathrm{OH})_{2}, \mathrm{MgO}, \mathrm{Mg}(\mathrm{OH})_{2}, \mathrm{CaO}$ e $\mathrm{CaSO}_{4}$

Duas hipóteses podem ser formuladas para descrever os resultados em função da solubilidade e basicidade dos compostos adicionados. Compostos insolúveis de caráter básico possuem afinidade por hidrogênios ionizáveis. Assim, quando adicionados à suspensão, retirariam hidrogênio de grupos Si-OH da superfície das partículas de sílica, facilitando a formação de ligações siloxano ( $\mathrm{Si}-\mathrm{O}-\mathrm{Si}$ ) entre partículas adjacentes e levando à gelificação pela formação de uma rede ramificada de partículas, de acordo o esquema a seguir:

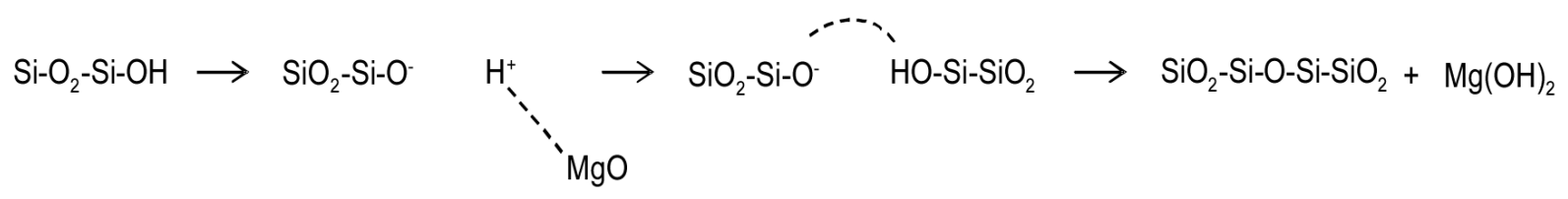

Já os compostos solúveis nessa faixa de pH (10) quando incorporados à suspensão liberariam cátions, que promoveriam a coagulação do sol servindo de ponte para união das partículas de sílica [2], como ilustrado na Fig. 4.

No primeiro caso, se enquadram os óxidos e hidróxidos de magnésio e cálcio. $O$ cálcio não é tão eficiente por ter menor afinidade pelo hidrogênio de grupos Si-OH [5] e ainda porque o íon $\mathrm{Ca}^{2+}$ é grande o suficiente para dificultar o contato direto entre as partículas de sílica, impedindo a formação de ligações Si-O-Si por efeito estérico [2].

No segundo caso, estão os cloretos e sulfatos de magnésio
Tabela III - Solubilidade de compostos inorgânicos em água a $18^{\circ} \mathrm{C}[6]$.

[Table III - Inorganic compounds solubility in aqueous solution at $18{ }^{\circ} \mathrm{C}$ [6].]

\begin{tabular}{cc}
\hline Compostos & Solubilidade $(\mathrm{g} / 100 \mathrm{~mL})$ \\
\hline $\mathrm{CaSO}_{4}$ & 0,20 \\
$\mathrm{MgSO}_{4}$ & 35,43 \\
$\mathrm{MgCl}_{2}$ & 55,81 \\
$\mathrm{CaCl}_{2}$ & 73,19 \\
\hline
\end{tabular}




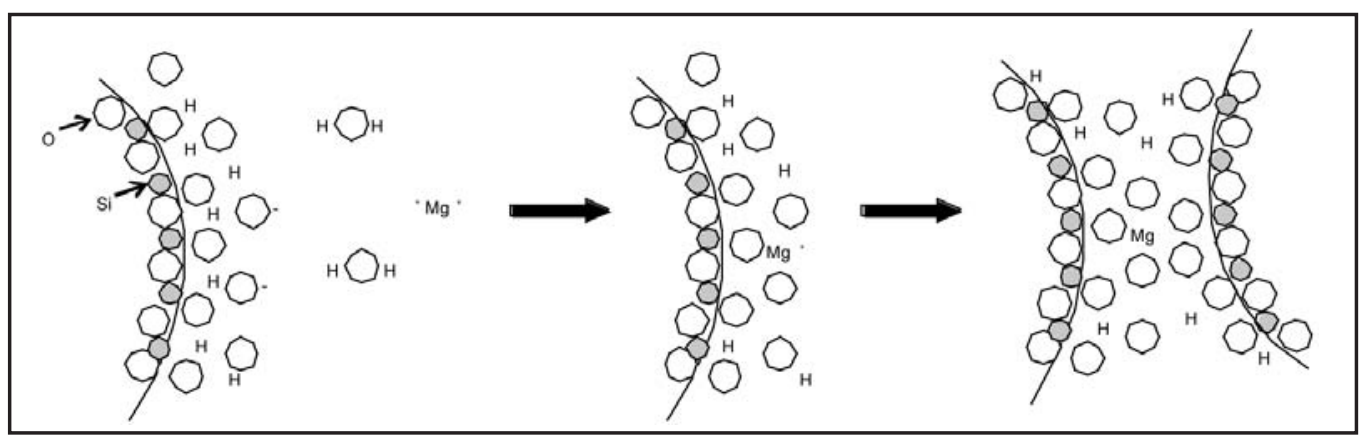

Figura 4: Consolidação do sol de sílica pelo do mecanismo de coagulação.

[Figure 4: Silica sol consolidation through coagulation mechanism.]

e cálcio. A eficiência na promoção da coagulação do sol está atrelada à solubilidade do sal, como se pode observar na Tabela III.

O sulfato de cálcio praticamente não é solúvel, o que explica sua ineficiência em promover a coagulação, mas, além disso, provavelmente também gera um efeito dispersante na alumina, uma vez que diminuiu drasticamente os valores dos módulos em relação à suspensão sem aditivo.

Esses resultados indicam uma tendência clara para que um determinado composto possa atuar como agente gelificante. A princípio, deve possuir caráter básico para ser capaz de reagir com hidrogênio da superfície da sílica e promover a formação do gel ou ser solúvel para que o cátion metálico atue como ponte para ligação das partículas de sílica, gerando coagulação.

Para confirmar a hipótese de que os óxidos e hidróxidos de magnésio e cálcio são capazes de acelerar a gelificação do sol de sílica e que seus cloretos e sulfatos promovem a coagulação desse sol, foram realizados ensaios de resistência mecânica (Fig. 5).

As amostras com $\mathrm{MgO}, \mathrm{Mg}(\mathrm{OH})_{2}, \mathrm{CaO}$ e $\mathrm{Ca}(\mathrm{OH})_{2}$ apresentaram maior resistência mecânica que aquelas com $\mathrm{MgCl}_{2}, \mathrm{MgSO}_{4}, \mathrm{CaCl}_{2}$ e $\mathrm{CaSO}_{4}$. Esse comportamento demonstra que a gelificação promove uma estrutura mais

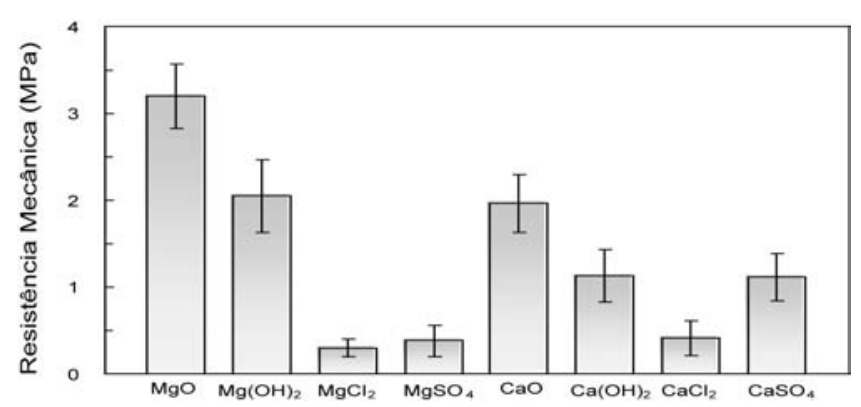

Figura 5: Resistência mecânica para amostras secas de alumina e sol de sílica com adição de diferentes compostos inorgânicos.

[Figure 5: Mechanical strength for dry alumina and silica sol samples with addition of different inorganic compounds.] homogênea e resistente que a coagulação. Apesar da taxa de aumento dos módulos G' e G” ser superior para as suspensões com adição dos sais (com exceção do $\mathrm{CaSO}_{4}$ ), a estrutura formada é composta de coágulos mais fortemente ligados internamente, mas que não são coesos entre si, como pode ser observado visualmente. Como resultado, os corpos não possuem estrutura homogênea como os que sofrem gelificação, apresentando menor resistência. $\mathrm{O}$ fato da suspensão $\mathrm{CaSO}_{4}$ ter apresentado corpos com resistência maior que os outros sais provavelmente se deve a um melhor empacotamento das partículas devido ao seu efeito dispersante. A formação de $\mathrm{CaSO}_{4} \cdot 2 \mathrm{H}_{2} \mathrm{O}$ (gipsita) também

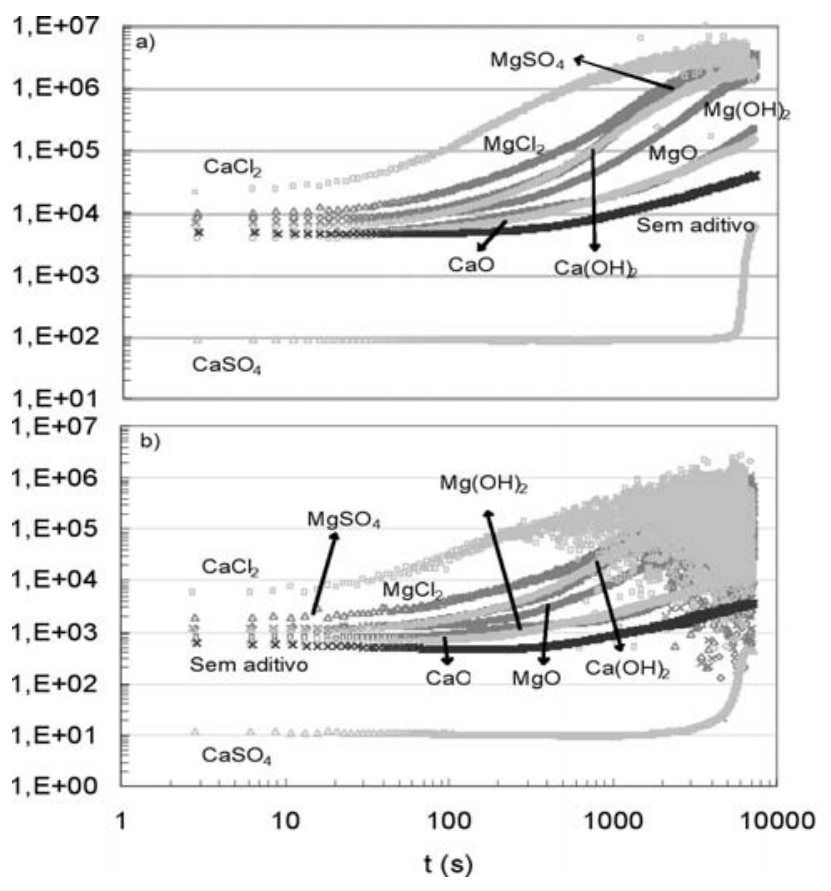

Figura 6: Suspensão de alumina e sol de sílica com adição de diferentes compostos inorgânicos a $8^{\circ} \mathrm{C}$; a) G' e b) G” em função do tempo.

[Figure 6: Alumina and silica sol suspension with addition of

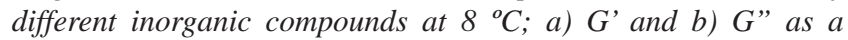
function of time.] 


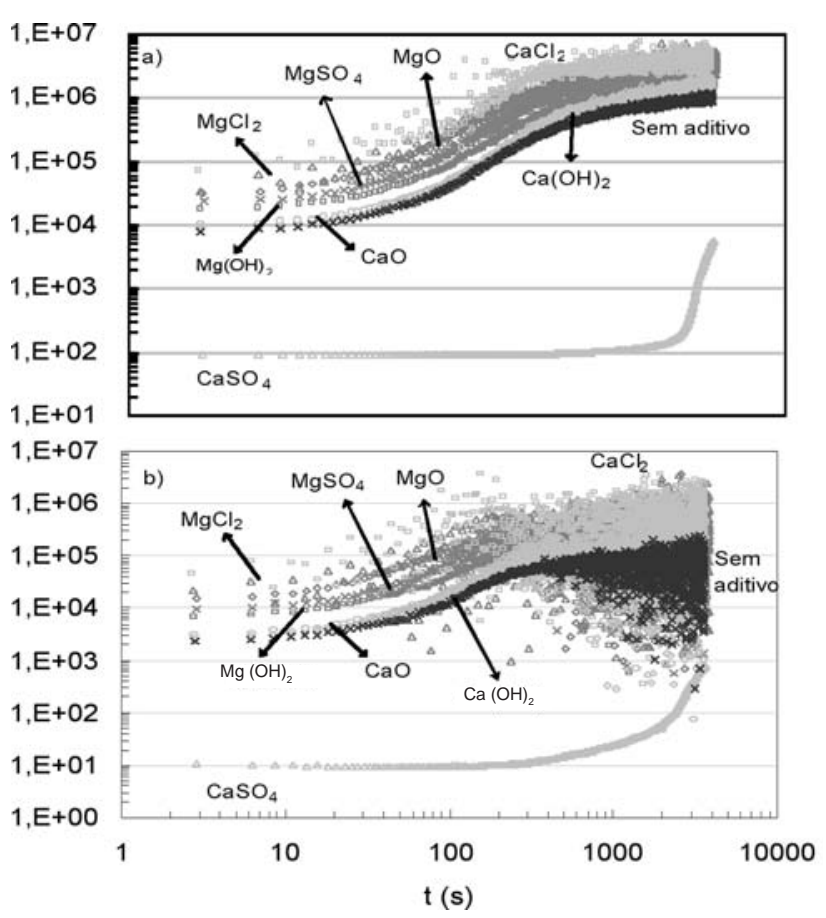

Figura 7: Suspensão de alumina e sol de sílica com adição de diferentes compostos inorgânicos a $50^{\circ} \mathrm{C}$; a) G' e b) G” em função do tempo.

[Figure 7: Alumina and silica sol suspension with addition of different inorganic compounds at $50{ }^{\circ} \mathrm{C}$; a) $G^{\prime}$ and b) $G$ ” as a function of time.]

não deve ser descartada.

As Figs. 6 e 7 apresentam resultados para as mesmas suspensões, porém em temperaturas de ensaio de 8 e $50{ }^{\circ} \mathrm{C}$, respectivamente.

A cinética de consolidação foi retardada a $8{ }^{\circ} \mathrm{C}$ e acelerada a $50^{\circ} \mathrm{C}$, indicando que o aumento de temperatura gera aumento da solubilidade dos compostos, quando solúveis, e da energia cinética das partículas, o que facilita a consolidação. A ordem de velocidade se manteve, com exceção do $\mathrm{MgO}$ e do $\mathrm{Ca}(\mathrm{OH})_{2}$ na temperatura de $50^{\circ} \mathrm{C}$. Tais variações foram pequenas e podem ser devidas a alterações na solubilidade desses compostos com o aumento da temperatura até $50{ }^{\circ} \mathrm{C}$.

\section{CONCLUSÕES}

O sol de sílica pode atuar como agente consolidador para suspensões cerâmicas, dispensando o uso de outros ligantes. Com uma aditivação adequada, a velocidade da gelificação pode ser projetada para que ocorra dentro de intervalos de tempo adequados para o processamento utilizado. Entre os agentes dispersantes testados o FS10 foi considerado o mais adequado baseado no intervalo de trabalhabilidade antes da consolidação. Verificouse que a velocidade de consolidação pode ser afetada pelo caráter básico, solubilidade e energia cinética do composto utilizado como agente gelificante. A quantidade de $\mathrm{MgO}$, o agente mais eficiente, deve ser calculada em função do tempo disponível para moldagem, que varia de acordo com o processo de conformação utilizado e da temperatura de processamento.

\section{AGRADECIMENTOS}

Os autores agradecem à Alcoa Alumínio S.A. pelo fornecimento das matérias-primas, à CAPES e à FAPESP pelo apoio à pesquisa e ao Dr. Jarem R. Garcia pelas suas sugestões.

\section{REFERÊNCIAS}

[1] S. Banerjee, Am. Ceram. Soc. Bull. 77, 10 (1988) 59-63.

[2] R. K. Iler, The Chemistry of Silica: solubility, polymerization, colloid and surface properties and biochemistry, John Wiley \& Sons, New York (1979) 172-439.

[3] G. Schramm, A Practical Approach to Rheology and Rheometry, $2^{\text {nd }}$ Ed., Gebrueder HAAKE GmbH, Karlsruhe (1998) 119-121.

[4] R. D. Anjos, R. Salomão, V. C. Pandolfelli, Anais do $49^{\circ}$ Cong. Bras. Cerâm., S. Pedro, SP (2005).

[5] J. E. Brady, J. R. Holum, Chemistry, the study of matter and its changes, $2^{\text {nd }}$ Ed., John Wiley \& Sons, New York (1973) cap. 9.

[6] Disponível em: http://carbonarium.dfly.com.br/ tcf002.htm - acessado em 01/03/05.

(Rec. 03/06/2005, Ac. 17/02/2006) 